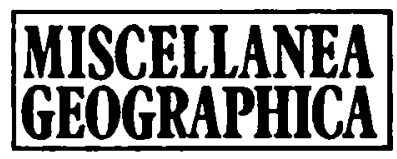

WARSZA WA 1996 VOL. 7

Irena Tsermegas

\title{
THE NATURAL AND THE ANTHROPOGENIC ELEMENTS IN THE RELIEF OF IKARIA ISLAND (GREECE)
}

\section{INTRODUCTION}

Ikaria is a small island (with the area of $255 \mathrm{sq} . \mathrm{km}$ ) located in the eastern part of the Aegean Sea. It can be treated as a representative fragment of a broader region, especially with respect to climate and geological structure, which has here a decisive influence on the relief. The rocks which dominate on the island are of crystalline character (granite-gneiss, gneiss, crystalline schist, crystalline limestone and granitoid). Only a limited fragment of the South-eastern coast is covered by sedimentary rocks (Papanikolaou, 1978).

The climate of Ikaria has typically mediterranean features. It has dry, hot summer seasons and warm, humid winters. The meteorological phenomena which help the relief forming processes (mainly an intensive precipitation and strong winds) appear here in a very much seasonal manner.

The analysis of natural and man-made or modified elements forming the relief of the island is mainly based upon the field observations of the author, made during the mapping of the modern morphogenetic processes. In view of the scale of the report only fundamental forms were accounted for.

\section{GENERAL MORPHOLOGICAL CHARACTERIZATION}

When considering the island as a whole we can distinguish a number of forms of the first order (Fig. 1). Their setting and their relation to the geological structure display certain regularities, which become less legible when the scale grows, i.e. when we pass over to the forms of the lower order.

The relief of Ikaria has a rejuvenated character. Distinct erosion valleys dismember the old planation surface. The appended geomorphological sketch (Fig. 1A) shows the directions of the main linear elements of the island's relief. They are mutually connected, which results on the one hand from their genetic interrelation, and on the other hand - from the geological structure (the forms refer to the tectonic directions and to the nature of rocks). 
One of the basic features of morphology of Ikaria is the polygenetic character of relief. Almost all forms depend first of all upon the pre-Quaternary geological structure. The surface of the island is strongly divided. The morphological axis of the SW-NE orientation is constituted by the 40 kilometer long Atheras ridge with the highest peak of $1042 \mathrm{~m}$ a.s.l. The whole surface is distinctly asymmetric. The southern and South-eastern parts have significant slope inclinations, often exceeding 45 , while the northern part is dominated by the well shaped deeply cut valleys, separated by long, distinct ridges. The forms appearing in the eastern part have the rectilinear (almost meridional) course, while the directions defined by the morphological lines of the western part of the island are quite varied.

\section{ANTHROPOGENIC FORMS SEEN AGAINST THE BACKGROUND OF THE NATURAL ONES}

Archaeological findings demonstrated that Ikaria was inhabited by humans already at the turn of the 3rd millennium B.C. (Melas, 1955). It can therefore be suspected that at that time the process of anthropogenic pressure on the island's relief had already started. The limited area made it necessary to use and develop even the least accesible mountain regions. Today the basic anthropogenic forms of relief on Ikaria include (in order of the area covered): terraced slopes, overbuilt slopes (with dispersed and dense constructions), road embankments and cuts, port basins, as well as artificial resorvoirs.

Even a cursory comparison of the sketches presenting natural and anthropogenic forms (Figs. 1A and 1B) gives the basis to presume that there exists a relation between these relief forms. The question arises whether (and if so: why) the spatial distribution of the areas transformed by human activity refers to the system defined by the ridge and water flow lines.

It turns out that:

1. The artificial nonlinear morphological elements (Fig. 1B) occupy mostly the moderately inclined surfaces $\left(15-30^{\circ}\right)$ at the feet of rocky walls and slopes, where conditions exist for the accumulation of weathering mantle, and therefore - for the persistence of a significant depth of the soil cover. These areas are usually located close to the coasts, but not directly over the sea. Such location results from the accessibility of freshwater and from the provision of security to the inhabitants in the historical past (e.g. in the form of shelter against the pirates).

2. The course of the main roads shows a distinct correlation with the basic morphological lines. Transport routes go along the valleys or coasts and only in few points cross the Atheras ridge. The ridge lines constitute the fabric of the natural forms, while roads are the element which joins the remaining anthropogenic elements so as to constitute a system. 


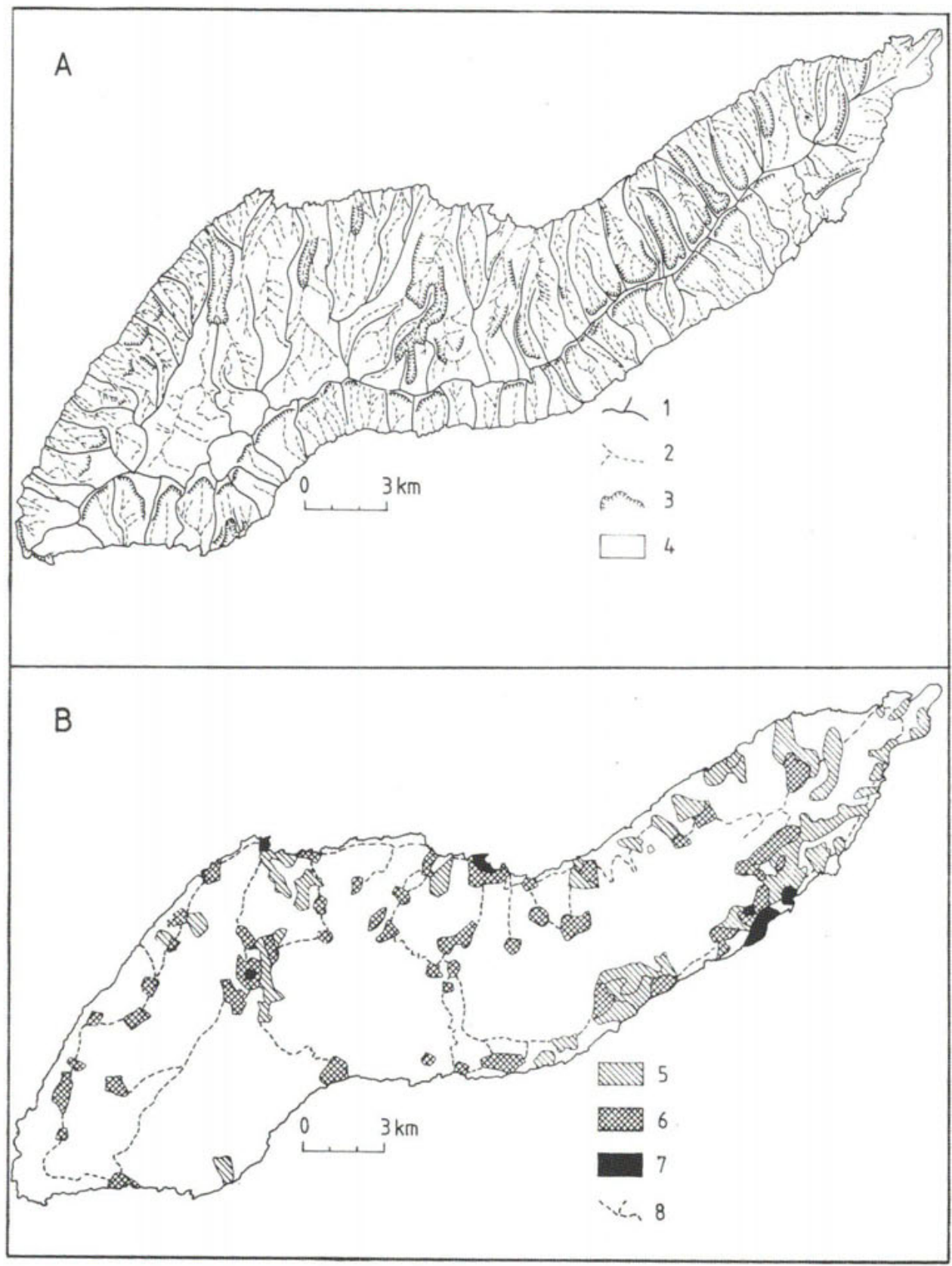

Fig. 1. Main elements of morphology of Ikaria

A. Natural form s: 1. Main ridge lines 2. Axes of erosion cuts (beds of permanent or periodical water flows) 3. Ledges of rocky walls sand steep slopes 4 . Denudation slopes.

B. Anthropogenic elements: 5. Agricultural terraces 6. Partly overbuilt agricultural terraces 7. Denselv overbuilt areas 8 . Main roads. 
The sketch of Fig. 1B includes only the areas over which men have established the new relief forms during almost 50 centuries. Currently, the direct anthropogenic pressure affects much smaller areas. The majority of the agricultural terraces are not used anymore. The diversity of the anthropogenic morphological elements which emerge more and more quickly increases, but the surface taken by these elements constantly decreases. This, however, does not mean that the relief of Ikaria is returning to the natural state. The modern human intervention concerns to a very high degree the entire environment. The anthropogenic relief forming processes take on a great importance. Human activity often leads to disastrous effects, such as mudslides, landslides and the like. This results in appearance of the "artificial relief" whose forms, however, take shape irrespective of the man's will. Even the apparently natural lines of Fig. 1A, denoting ridges, waterflows and ledges, bear the traces of the anthropogenically accelerated processes of erosion and denudation.

\section{REFERENCES}

Melas I., 1955, History of the Ikaria island, Athens.

Papanikolau D.J., 1978, Contribution to the geology of Ikaria island, Aegean Sea (in Greek), Annales Géologiques des Pays Helléniques, vol. XXIX/1, Athens, p. 1-28. 